\title{
Stem cell factor-dependent mast cell proliferation, maturation and activity can be regulated by inhibitory receptors
}

\author{
EWA BRZEZIŃSKA-BEASZCZYK, EDYTA BĄBOLEWSKA
}

Department of Experimental Immunology, Medical University of Łódź, Poland

\begin{abstract}
Mast cells play an important role in many physiological and pathological processes. That is why, the factors and the mechanisms regulating mast cell development, maturation, proliferation, and activity within tissues are of special importance. More and more data indicate that mast cells express inhibitory receptors. Furthermore, there are findings that inhibitory receptors can modulate IgE-dependent mast cell activity, thereby influencing the intensity of allergic processes. Bearing in mind that c-kit (CD117)specific stem cell factor (SCF) not only affects mast cell activity but also strongly promotes mast cell development and proliferation, it is extremely interesting whether inhibitory receptors modulate $S C F$-mediated mast cell response. Nowadays, certain data suggest that some inhibitory receptors, such

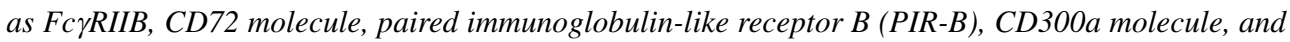
gp49B1 glycoprotein, can affect CD117-dependent mast cell activity and proliferation.
\end{abstract}

Key words: mast cells, inhibitory receptors, mast cell development, stem cell factor.

(Centr Eur J Immunol 2013; 38 (1): 134-140)

\section{Introduction}

More and more data indicate that many different regulatory mechanisms are needed to direct and control immune responses. Nowadays, it seems that the most important in the control of immune processes is balance between immune activation and inhibition. Notably, counterbalance between positive and negative signals prevents from inappropriate activation of the immune system and participates in immune response termination. Some information suggests that the loss of inhibitory signals may result in autoreactivity and, in consequence, may lead to autoimmune diseases. The disturbance in interplay of activation and inhibition results in the immune system hyperactivity and development of unchecked inflammatory responses as well.

During the 1980s more and more data suggested that cellular proliferation, differentiation and activity are regulated through the use of different cell surface molecules and receptors. Moreover, it was hinted that cell biology is controlled via equilibration between activating signals and suppressive signals. In 1998, Lanier unambiguously documented that NK cell-mediated cytotoxicity and cytokine expression are regulated by opposing signals from receptors that activate and inhibit effector functions [1]. Furthermore, Lanier suggested that NK cell inhibitory receptors are members of a larger set of molecules and formulated the term "inhibitory receptor superfamily" [2]. Nowadays, it is unquestionable that different inhibitory receptors play crucial role in the regulation of cellular biology. Whilst most of the data on inhibitory receptors have emerged from studies on NK cell function, B and T cell receptor signaling, it is well documented that these receptors influence the activity of macrophages, dendritic cells, neutrophils and eosinophils as well [3, 4].

A members of inhibitory receptor superfamily can be determined by a consensus amino acid sequence, named the immunoreceptor tyrosine-based inhibitory motif (ITIM), located in the intracytoplasmic domain of these molecules. The ITIM motif was originally identified in the cytoplasmic domain of Fc $\gamma$ RIIB receptor, within the 13-amino acid sequence AENTITYSLLKHP. The classic ITIM sequence is composed of 6 amino acids (I/V/LxYxxL/V), where $\times$ represents any amino acid. Inhibitory receptors can express either one or several ITIM domains [3-5]. Engage-

Correspondence: Ewa Brzezińska-Błaszczyk, Department of Experimental Immunology, Medical University of Łódź, Pomorska 251, 92-213 Łódź, Poland, tel. +48 4267573 06, fax +48 4267573 06, e-mail: ewab@csk.umed.lodz.pl 
ment of inhibitory receptors with their ligands resulted in ITIM motif phosphorylation usually by Src-family kinases. It provides a docking site for the recruitment of cytoplasmic phosphatases having a Src homology 2 (SH2) domain such as SH2-containing phosphatase-1 (SHP-1) and/or SH2-containing phosphatase-2 (SHP-2) and/or SH2 domain-bearing inositol 5-phosphatase-1 (SHIP-1). These enzymes most likely dephosphorylate tyrosine residues that provides docking sites for signaling kinases connected with activating receptor pathways [3-5]. It seems that in order to achieve the inhibitory effect ITIM-bearing molecules must co-aggregate with activating receptors, however, in certain situations such co-ligation of two receptors is not required [4-6].

There are two different groups of inhibitory receptors, i.e. immunoglobulin-like superfamily receptors and C-type lectin inhibitory receptors. The immunoglobulin-like inhibitory receptors are characterized by the presence of one or more immunoglobulin-like domains in extracellular portion. The C-type lectin inhibitory receptors are calcium-dependent carbohydrate-binding proteins. These calcium-dependent molecules bind carbohydrates through a specific domain named CDR (carbohydrate-recognition domain) [3, 4].

\section{Mast cell characteristics}

Mast cells are multifunctional long-lived secretory cells widely distributed throughout the vascularized tissues and serosal cavities. These cells have the potential to secrete a wide spectrum of biologically active mediators, cytokines, and chemokines [7, 8]. Mast cell mediators can be divided into preformed, granule-associated substances and de novo synthesized compounds. Preformed mediators are stored in secretory granules and on activation they are released into the tissues within minutes. Granule-associated mediators include histamine, neutral proteases, metalloproteinases (MMPs), proteoglycans, as well as some preformed cytokines, such as interleukin (IL)-3, IL-4, IL-6, IL-10, tumor necrosis factor (TNF) and chemokine CXCL8. Newly generated mediators comprise arachidonic acid metabolites, such as leukotrienes (LTs), prostaglandins (PGs), platelet activating factor (PAF), and de novo synthesized cytokines, including various ILs, TNF, interferons (IFNs), a lot of growth factors, such as stem cell factor (SCF), nerve growth factor (NGF) and granulocyte-macrophage colony stimulating factor (GM-CSF), as well as different chemokines. Moreover, there are some data that mast cells can synthesize corticotrophin-releasing factor $(\mathrm{CRH})$ and its structurally related urocortin [9], endothelin-1 (ET-1) [10], amphiregulin [11], as well as granzyme B [12]. Mast cells are the source of some antimicrobial peptides such as human cathelicidin LL-37 or murine cathelicidin-related CRAMP and $\beta$-defensin- 4 as well [13].

It should be underlined that mast cell mediators can exert diverse effects. Some mediators, cytokines and chemokines promote the development of inflammation, while some of the mast cell products exhibit anti-inflammatory and/or immunosuppressive properties. Mast cell mediators strongly influence the development, maturation, migration, survival, and function of immune cells. What is more, several mast cell products affect B lymphocyte development and function, and some mast cell derived cytokines/chemokines influence the polarization of $\mathrm{T}$ cell subsets. Certain mediators have angiogenic properties or take part in the turnover of extracellular matrix (ECM) proteins and in remodeling of structural elements of tissues [7, 14-16].

Mast cells express numerous different surface receptors, and thereby a lot of various factors can activate these cells to mediator release. Mast cells constitutively express the high affinity receptor for IgE (FceRI) [17] as well as other receptors for Fc portion of immunoglobulins [18]. Indisputably, mast cells have different receptors specific for cytokines and chemokines [19], for several neuropeptides and hormones, and for certain complement system activation products [20]. What is more, mast cells have also been found to express $\mathrm{H} 1, \mathrm{H} 2$, and $\mathrm{H} 4$ histamine receptors [21, 22], cysteinyl (cys)LT1 and cysLT2 receptors [23], and protease activated receptor 2 (PAR2) [24] as well. It is well documented that these cells have Toll-like receptors (TLRs) [25], molecules specific for pathogen associated molecular patterns (PAMPs).

Considering that mast cells have the potential to secrete diverse biologically active substances in response to activation with a variety of stimuli, it seems obvious that these cells play an important role in many physiological and pathological processes. Undoubtedly, mast cells exert a vital role in maintaining homeostasis by participating in tissue remodeling and repair, stimulation of angiogenesis, and by vascular permeability regulation $[7,14,15,26]$. These cells take part in innate and acquired immunity [27, 28]. Mast cells are also known to participate in the inflammatory processes [15, 26, 29]. What is more, these cells play a role in host defense against bacteria and viruses, and are important sentinels of the immune system in defense against parasites [30-32]. Mast cells are also implicated in diverse pathophysiological processes, such as allergic diseases, various autoimmune diseases, and other chronic inflammatory diseases [14, 29, 33, 34].

Mast cells are derived from CD13+CD34+CD117+ multipotent hematopoietic stem cells in bone marrow. Mast cell progenitors exit the bone marrow, enter into the blood and circulate in small numbers as mononuclear agranular cells. Subsequently, developing mast cells migrate to peripheral tissues where they terminate their maturation and differentiation under the influence of local micromilieu. It should be underlined that although mature mast cells are highly differentiated, they retain an extensive proliferation potential $[35,36]$. Maturation and differentiation of mast cells are regulated by various humoral factors. It is well doc- 
umented that mast cell proliferation is promoted by some cytokines, including IL-3, IL-4, IL-9, IL-10, and IL-13. Maturation of these cells is also affected, either positively or negatively, by IL-5, IL-6, IL-12, TNF, NGF, transforming growth factor (TGF)- $\beta$, and IFN- $\gamma$ [37]. Some data indicate that mast cell development is also influenced by $\mathrm{PGE}_{2}$ [38]. However, the most important factor for mast cell proliferation and maturation is SCF. This cytokine is constitutively produced by fibroblasts, keratinocytes, epithelial cells, endothelial cells, and marrow stromal cells and acts via the tyrosine kinase receptor c-kit (CD117) [39]. It should be stressed that CD117 is expressed on mast cells at all stages of their differentiation.

It is well documented that activity, migration, and survival of mature mast cells within tissues are regulated by different humoral factors, including many cytokines [40-42]. Certainly among cytokines, SCF plays an important role in modulating tissue mast cell biology. It is well established that SCF promotes mast cell survival by suppressing apoptosis [43] and induces mast cell adhesion to connective tissue matrix [44]. This cytokine is also a potent mast cell chemoattractant [45] thereby influencing mast cell number within tissues. Some data prove that SCF can directly stimulate mast cells to degranulation and histamine release [46] as well as to synthesis and release of IL-6 [47]. What is more, the exposure of mast cells to SCF results in up-regulation of CCL2 mRNA expression, de novo expression of CCL3 mRNA, and release of CCL2 [48]. It was also noticed that the administration of SCF intradermally in vivo, at doses as low as $149 \mathrm{fM} /$ site, induces activation of cutaneous mast cells and evokes mast cell-dependent acute inflammatory response [49]. It is also demonstrated that SCF can influence IgE-dependent mast cell activity. A brief preincubation of mast cells with SCF, at concentrations 10-100-fold lower than that required to promote cell proliferation, enhances histamine release as well as $\mathrm{LTC}_{4}$ and $\mathrm{PGD}_{2}$ synthesis by mast cells in response to IgE-dependent stimulation $[46,50]$. This cytokine in synergy with antigen causes significant increase of mast cell degranulation and cytokine production [51]. On the contrary, prolonged exposure of mast cells to SCF resulted in marked attenuation of FceRI-mediated degranulation as well as IL-6, TNF, IL-13 and CCL2 production [52]. In mice, chronic treatment with SCF causes diminution of the severity of IgE-dependent anaphylactic reactions [53]. These data suggest that SCF can play an important role in mast cells effector function regulation, especially in allergic processes.

\section{Mast cell inhibitory receptors}

Over the past several years, it has become clear that mast cells express a number of surface inhibitory receptors that can influence mast cell development and activity within tissues [54-56]. Among immunoglobulin-like superfamily of inhibitory receptors mast cells express Fc $\gamma$ RIIB, paired immunoglobulin-like receptor B (PIR-B), molecule CD300a, glycoprotein gp49B1, molecule CD200R, molecule CD305, molecule CD172a, platelet endothelial cell adhesion molecule (PECAM-1), molecule allergin-1, and members of the sialic acid-binding immunoglobulin-like lectin family (Siglecs). Out of C-type lectin inhibitory receptors mast cells express mast cell function-associated antigen (MAFA) and molecule CD72. Basic information about mast cell inhibitory receptors is summarized in Table 1.

There are data that certain inhibitory receptors can modulate IgE-dependent mast cell activity thereby influencing the intensity of allergic processes. It was demonstrated that co-aggregation of Fc $\gamma$ RIIB, CD300a, gp49B1, PIR-B or CD172a with FceRI significantly reduces IgE-dependent mast cell activation [56, 57]. It was also stated that activation of inhibitory receptors, such as Fc $\gamma$ RIIB, gp49B1, PECAM-1 or CD300a, via their specific ligand resulted in the decrease of mast cell anaphylactic response [57]. Moreover, there is extremely intriguing information that gp49B1 in cooperation with its natural ligand, that is integrin $\alpha v \beta 3$, can play an essential role in the suppression of allergic response [58]. It was also suggested that cooperation between PIR-B and its natural ligand, i.e. MHC class I molecule, constitutively delivers negative signaling into mast cells and regulates cellular activation induced by $\operatorname{IgE}$ [59]. Bearing in mind the crucial role of SCF not only in the promotion and regulation of mast cell development, but also in the modulation of mature mast cell activity within tissues, especially in allergic processes, it is extremely interesting whether inhibitory receptors can influence SCF-mediated mast cell response.

\section{Regulation of SCF-mediated mast cell proliferation and maturation via inhibitory receptors}

As far as immunoglobulin-like inhibitory receptors are concerned, the best investigated and described is Fc $\gamma$ RIIB. This receptor belongs to a large family of molecules characterized by their ability to bind $\mathrm{IgG}$ constant $(\mathrm{Fc})$ region, however the affinity of Fc $\gamma$ RIIB for IgG is low. Almost all cell populations involved in immunological processes, including B lymphocytes, T lymphocytes, macrophages, monocytes, neutrophils, dendritic cells, platelets, natural killer cells, and basophils, express this receptor. Expression of Fc $\gamma$ RIIB molecule is well documented also on mast cells, but mainly on cultured cell lines such as rat cell line RBL-2H3, murine mast cells derived from bone marrow (BMMCs), mast cells cultured from umbilical cord blood (CBMCs), and HMC-1 cells [56]. Currently, more and more data indicate that Fc $\gamma$ RIIB can modulate mast cell activity in anaphylactic reactions. It has been proven in in vitro experiments that co-aggregation of Fc $\gamma$ RIIB with FceRI resulted in significant inhibition of IgE-mediated mast cell degranulation and preformed mediator release as well as de novo cytokine synthesis. The influence of Fc $\gamma$ RIIB on 
Table 1. Mast cell inhibitory receptors [55, 56]

\begin{tabular}{|c|c|c|c|}
\hline Receptor & Physiological ligand & Receptor structure & Expression \\
\hline \multicolumn{4}{|c|}{ Immunoglobulin-like receptors } \\
\hline Fc $\gamma$ RIIB & $\operatorname{IgG}$ & $\begin{array}{l}2 \text { Ig-like domains } \\
1 \text { ITIM motif }\end{array}$ & BMMCs, CBMCs, HMC-1, RBL-2H3 \\
\hline PIR-B & MHC I & $\begin{array}{l}6 \text { Ig-like domains } \\
4 \text { ITIM motifs }\end{array}$ & BMMCs, progenitor fetal spleen-derived MCs \\
\hline CD300 & phosphatidylserine & $\begin{array}{l}1 \text { Ig-like domain } \\
4 \text { ITIM motifs }\end{array}$ & BMMCs, CBMCs, HMC-1, human lung MCs \\
\hline gp49B1 & integrin $\alpha v \beta 3$ & $\begin{array}{l}2 \text { Ig-like domains } \\
2 \text { ITIM motifs }\end{array}$ & BMMCs, RBL-2H3, murine peritoneal MCs \\
\hline CD200R & CD200 & $\begin{array}{l}2 \text { Ig-like domains } \\
\text { lack of ITIM motif }\end{array}$ & BMMCs, CBMCs, human and murine cutaneous MCs \\
\hline Siglecs & various & $\begin{array}{l}\text { variable number of Ig-like } \\
\text { domains and ITIM motifs }\end{array}$ & CBMCs, HMC-1, LAD, PBMCs, RBL-2H3 \\
\hline CD305 & collagen type XVII & 1 Ig-like domain 2 ITIM motifs & HMC-1 \\
\hline CD172a & $\mathrm{CD} 47$ & $\begin{array}{l}3 \text { Ig-like domains } \\
4 \text { ITIM motifs }\end{array}$ & $\begin{array}{l}\text { CBMCs, HMC-1, human lung, gastrointestinal tract } \\
\text { and cutaneous MCs, BMMCs isolated from patients } \\
\text { with systemic mastocytosis }\end{array}$ \\
\hline allergin-1 & unknown & $\begin{array}{l}1 \text { or } 2 \text { Ig-like domains } \\
1 \text { ITIM motif }\end{array}$ & BMMCs, RBL-2H3 \\
\hline PECAM-1 & integrin $\alpha v \beta 3$ & $\begin{array}{l}6 \text { Ig-like domains } \\
2 \text { ITIM motifs }\end{array}$ & BMMCs, RBL-2H3, murine peritoneal MCs \\
\hline \multicolumn{4}{|c|}{ C-type lectin receptors } \\
\hline MAFA & unknown & 1 ITIM motif & RBL-2H3 \\
\hline CD72 & CD100 & 1 ITIM motif & HMC-1, LAD, PBMCs \\
\hline
\end{tabular}

FceRI-dependent mast cell activation was thoroughly documented in vivo as well [57].

The effect of FcyRIIB on SCF-dependent mast cell proliferation and differentiation was studied by Malbec et al. $[60,61]$. It should be stressed that the experiments were performed on mast cells differentiated in vitro from murine bone marrow, i.e. BMMCs, which represent a key type of primary immature cells. It should be also remarked that to the study mast cell proliferation thymidine incorporation assay was used. The authors stated that BMMCs generated from Fc $\gamma$ RIIB-deficient mice and BMMCs obtained from wild-type mice, when incubated for $24 \mathrm{~h}$ with SCF, incorporated comparable amount of thymidine. However, coaggregation of CD117 with Fc $\gamma$ RIIB, via anty-kit specific IgG antibodies which bind simultaneously to CD117 by their Fab portion and to Fc $\gamma$ RIIB by their Fc portion, in BMMCs from wild-type mice resulted in inhibition of c-kit-mediated BMMC proliferation, as assessed by thymidine incorporation assay. The inhibition of mast cell proliferation correlates with a blockade of the G1-S transition, during the cell cycle. It was also documented that co-aggregation of CD117 with Fc $\gamma$ RIIB resulted in tyrosyl-phospory- lation of Fc $\gamma$ RIIB, which selectively recruited phosphatase SHIP. These observations strongly indicated that Fc $\gamma$ RIIB is a functional molecule which prevents excessive mast cell proliferative response and negatively regulates CD117induced proliferation.

The multiplication of cells, their survival and death are governed by complex mechanisms of cell cycle control. Without any doubt the most important regulators of the cell division cycle are cyclins. These proteins regulate the cell cycle by binding and activating cyclin-dependent kinases (Cdks). Phosphorylation of specific proteins by cyclin-Cdk complexes activates different processes that conduct the cell cycle in a timely manner [62]. It was demonstrated that CD117 aggregation in BMMCs caused significant increase in intracellular levels of cyclins D2, D3, and A, while coligation of CD117 with Fc $\gamma$ RIIB resulted in no change of cyclin levels. Inhibition of cyclin levels following co-aggregation of $c$-kit with Fc $\gamma$ RIIB correlated with suppression of mast cell proliferation [63].

Aside from Fc $\gamma$ RIIB mast cell growth and proliferation can be modulated via CD72 molecule, C-type inhibitory receptor. This molecule is predominantly expressed on 
B-lineage cells and can affect some activities of B cells [64]. CD72 is also expressed on T cells, NK cells, dendritic cells, and macrophages $[64,65]$. This molecule was found to be expressed on peripheral blood-derived mast cells (PBMCs), and mast cell lines HMC and LAD, as well. It has been indicated that co-aggregation of CD72 molecule with FceRI does not affect IgE-mediated mast cell degranulation and preformed mediator release [66]. On the contrary, there are convincing data that this inhibitory receptor can strongly influence mast cell growth and proliferation. Kataoka et al. [66] documented that concurrent action of CD117 ligand, i.e. SCF, and CD72 ligand, i.e. CD100 protein or CD72 agonistic antibodies (BU40), resulted in a marked reduction in the ratio of mast cells in the $\mathrm{G} 2 / \mathrm{M}+\mathrm{S}$ phases of cell cycle, indicating cell growth arrest. Moreover, CD100 protein as well as CD72 agonistic antibodies significantly diminished the proliferation of human mast cells (PBMC, HMC and LAD) as determined by bromodeoxyuridine (thymidine analogue) incorporation into DNA. What is more, mast cells treated with SCF in the presence of BU40 antibodies or CD100 protein showed a substantial increase in tyrosine phosphorylation of CD72, which was linked to a marked enhancement of the SHP-1 association with CD72. These events correlated with SFKs and ERK1/2 but not PI3K/AKT and Stat 3 dephosphorylation, the crucial signaling molecules which participate in the CD117-dependent pathway.

It seems to be of great importance to understand the mechanisms underlying mast cell migration into and within tissues. There are many factors that regulate migration of mast cell progenitors from the blood into tissues and the migration of mature mast cells within tissues leading to the rapid local accumulation that occurs in diverse pathological conditions [42]. It is well documented that SCF is one of the most important mast cell chemoattractant [45]. Thus, it is extremely interesting that the ligation of CD72 significantly reduced SCF-mediated mast cell chemotaxis [66].

There are data indicating that FceRI-dependent mast cell activation is strongly modulated by PIR-B molecule [57]. Sparse data suggest that mast cell proliferation can be also affected by this inhibitory receptor. Chen et al. [67] stated that coordinated ligation of PIR-B and c-kit led to suppression of SCF-induced proliferative response of mast cells.

Molecule CD300a is expressed on NK cells, T cell subsets, granulocytes, monocytes, and dendritic cells [55, 56]. The expression of this molecule is well documented on BMMCs, CBMCs, and HMC, as well [56]. It is established that CD300a modulates mast cell activity in anaphylactic reaction [57]. Bachelet et al. [68] indicated that CD300a can also affect mast cell maturation and survival. Bispecific antibodies linking CD117 with CD300a significantly inhibited CBMC transition into fully mature mast cells by $50 \%$, as evaluated by flow cytometry analysis of tryptase. Additionally, when cultured with Kit-CD300a bispecific antibodies, in the presence of SCF, human mature mast cell survival dramatically decreased.

\section{Inhibitory receptors can affect SCF-mediated mast cell activation}

Taking into account that SCF can directly stimulate mast cells to mediator and cytokine/chemokine release it seems to be important whether inhibitory receptors affect CD117dependent activation. Currently, there are some data that SCF-mediated mast cell stimulation is controlled by gp49B1 glycoprotein, CD300a, and CD72 molecules.

Feldweg et al. [69] thoroughly documented the role of gp49B1 in regulation of SCF-dependent mast cell activity. They noticed that intradermal injection of SCF induced tissue swelling in $g p 49 B^{+/+}$mice. In contrast, tissue swelling challenged with injection of SCF in $g p 49 B^{-1-}$ mice was significantly greater than that in $g p 49 B^{+/+}$mice. Moreover, tissue swelling remained meaningly greater in $g p 49 B^{-1-}$ mice for 8 hours after injection and returned to baseline by 24 hours. In the tissues of $g p 49 B^{-1-}$ mice 1 hour after SCF injection edema was substantially greater, compared with the edema in $g p 49 B^{+/+}$mice, as evaluated by histological analysis. In addition, one hour after SCF injection $g p 49 B^{-1-}$ mice had threefold more degranulating mast cells than $g p 49 B^{+/+}$mice. Taken together, all these observations clearly indicated that $g p 49 B 1$-deficient mast cells are more susceptible to SCF-induced activation in situ. The effects of receptor antagonists for mast cell granule-derived and lipidderived mediators on SCF-induced tissue swelling were studied, as well. When $g p 49 B^{+/+}$and $g p 49 B^{-/-}$mice were pretreated with antagonists of the serotonin type 1,2 , and 7 receptors and antagonist of histamine type 1 receptors, SCF-induced tissue swelling was reduced up to $90 \%$ and $62 \%$, respectively. Antagonist of the type 1 and 2 cysLT receptors reduced SCF-induced tissue swelling by $20 \%$ and $40 \%$ in $g p 49 B^{+/+}$and $g p 49 B^{-/-}$mice, respectively. When $g p 49 B^{-1}$ mice were pretreated with all three inhibitors before SCF injection, tissue swelling was reduced by $95 \%$. These findings indicate that $g p 49 B 1$ modulates the release of mast cell mediators in response to SCF stimulation in vivo.

There are also data that SCF-dependent mast cell activity can be regulated by CD300a and CD72 molecules. Bachelet et al. [68] determined that CD300a with CD117 coaggregation via bispecific antibodies resulted in inhibition of SCF-induced mast cell activation, as stated by the measurement of tryptase activity. In addition, SCF-induced calcium influx was inhibited by CD117-CD300a co-aggregation as well. Furthermore, CD300a-CD117 co-ligation abrogated SCF-mediated HMC-1 degranulation and $\beta$-hexozaminidase release. Upon c-kit linking, CD300a underwent rapid phosphorylation and recruited SHIP-1 but not SHP-1. Additionally, CD300a regulated CD117 signaling in vivo, as well. Treatment with CD117-CD300a bispecific antibodies simultaneously with administration of SCF completely abrogated skin mast cell degranulation and, in consequence, caused the decrease in SCF-induced cutaneous reaction intensity. Kataoka et al. [66] documented that concurrent CD117 activation 
by SCF and CD72 by CD100 or anti-CD72 antibodies significantly inhibited mast cell CCL2 synthesis as well as degranulation and $\beta$-hexosaminidase release.

\section{Concluding remarks}

Mast cells play an important role in diverse physiological processes, take part in mechanisms of both innate and adaptive defense, and participate in the course of many pathological processes. That is why, the factors and the mechanisms regulating mast cell development, maturation, survival, and activity within tissues are of special importance. Since the discovery of inhibitory receptors, growing evidence indicates that these molecules strongly affect cellular biology. Inhibitory receptors can influence mast cell activity, as well. It is very intriguing that some inhibitory molecules, via interaction with their natural ligands, modulate physiological mast cell activity. Keeping in mind the essential role of mast cells in allergic processes, extremely important are observations that some inhibitory receptors affect IgE-induced mast cell response. SCF, acting via c-kit receptor, can directly stimulate mast cells to degranulation and preformed mediator release as well as to synthesis de novo different cytokines and chemokines. Furthermore, without any doubt SCF is one of the key growth factor regulating mast cell development, maturation, proliferation, and survival in the physiological conditions. However, it is well known that the interaction between SCF and mutated c-kit receptor may cause enhanced mast cell proliferation and, in consequence, may lead to mastocytosis [70]. Additionally, it should be emphasized that mastocytosis is partially a result of the presence of "overactive" c-kit receptor. For this reason the mechanisms responsible for negative regulation of c-kit signaling should be recognized. Moreover, the knowledge about the influence of inhibitory receptors on SCF-mediated mast cell proliferation could provide the basics for developing new therapeutic approaches to mast cell proliferative disorders [71].

This work was supported by grant from the Medical University of Łódź (grant 503/6-164-01/503-01).

\section{References}

1. Lanier LL (1998): NK cell receptors. Annu Rev Immunol 16: 359-393.

2. Lanier LL (1997): Natural killer cells: from no receptors to too many. Immunity 6: 371-378.

3. Ravetch JV, Lanier LL (2000): Immune inhibitory receptors. Science 290: 84-89.

4. Munitz A (2010): Inhibitory receptors on myeloid cells: new targets for therapy? Pharmacol Ther 125: 128-137.

5. Vivier E, Daëron M (1997): Immunoreceptor tyrosine-based inhibition motifs. Immunol Today 18: 286-291.

6. Cooper MD (2008): Inhibition of immune cell function. Immunol Rev 224: 7-10.
7. Heib V, Becker M, Taube C, Stassen M (2008): Advances in the understanding of mast cell function. Br J Haematol 142: 683-694.

8. Gilfillan AM, Austin SJ, Metcalfe DD (2011): Mast cell biology: introduction and overview. Adv Exp Med Biol 716: 2-12.

9. Kempuraj D, Papadopoulou NG, Lytinas M, et al. (2003): Corticotropin-releasing hormone and its structurally related urocortin are synthesized and secreted by human mast cells. Endocrinology 145: 43-48.

10. Nagasaka A, Matsue H, Matsushima H, et al. (2008): Osteopontin is produced by mast cells and affects IgE-mediated degranulation and migration of mast cells. Eur J Immunol 38: 489-499.

11. Okumura S, Sagara H, Fukuda T, et al. (2005): FceRI-mediated amphiregulin production by human mast cells increases mucin gene expression in epithelial cells. J Allergy Clin Immunol 115: 272-279.

12. Pardo J, Wallich R, Ebnet K, et al. (2007): Granzyme B is expressed in mouse mast cells in vivo and in vitro and causes delayed cell death independent of perforin. Cell Death Differ 14: 1768-1779.

13. Di Nardo A, Vitiello A, Gallo RL (2003): Cutting edge: mast cell antimicrobial activity is mediated by expression of cathelicidin antimicrobial peptide. J Immunol 170: 2274-2278.

14. Rao KN, Brown MA (2008): Mast cells: multifaceted immune cells with diverse roles in health and disease. Ann NY Acad Sci 1143: 83-104.

15. Galli SJ, Tsai M (2008): Mast cells: versatile regulators of inflammation, tissue remodeling, host defense and homeostasis. J Dermatol Sci 49: 7-19.

16. Lundequist A, Pejler G (2011): Biological implications of preformed mast cell mediators. Cell Mol Life Sci 68: 965-975.

17. Kinet JP (1999): The high-affinity receptor (FceRI): from physiology to pathology. Annu Rev Immunol 17: 931-972.

18. Tkaczyk C, Okayama Y, Metcalfe DD, Gilfillan AM (2004): Fcy receptors on mast cells: activatory and inhibitory regulation of mediator release. Int Arch Allergy Immunol 133: 305-315.

19. Juremalm M, Nilsson G (2005): Chemokine receptor expression by mast cells. Chem Immunol Allergy 87: 130-144.

20. Nilsson G, Johnell M, Hammer CH, et al. (1996): C3a and C5a are chemotaxins for human mast cells and act through distinct receptors via a pertussis toxin-sensitive signal transduction pathway. J Immunol 157: 1693-1698.

21. Lippert U, Artuc M, Grützkau A, et al. (2004): Human skin mast cells express $\mathrm{H} 2$ and $\mathrm{H} 4$, but not $\mathrm{H} 3$ receptors. J Invest Dermatol 123: 116-123.

22. Godot V, Arock M, Garcia G, et al. (2007): $\mathrm{H}_{4}$ histamine receptor mediates optimal migration of mast cell precursors to CXCL12. J Allergy Clin Immunol 120: 827-834.

23. Austen KF (2005): The mast cell and the cysteinyl leukotrienes. Novartis Found Symp 271: 166-175.

24. Lohman RJ, Cotterell AJ, Barry GD, et al. (2012): An antagonist of human protease activated receptor-2 attenuates PAR2 signaling, macrophage activation, mast cell degranulation, and collagen-induced arthritis in rats. FASEB J 26: 2877-2887.

25. Brzezińska-Błaszczyk E, Wierzbicki M (2010): Mast cell Tolllike receptors (TLRs). Postepy Hig Med Dosw 64: 11-21.

26. Crivellato E, Ribatti D (2005): Involvement of mast cells in angiogenesis and chronic inflammation. Curr Drug Targets Inflamm Allergy 4: 9-11.

27. Galli SJ, Nakae S, Tsai M (2005): Mast cells in the development of adaptive immune responses. Nat Immunol 6: 135-142.

28. Tete S, Tripodi D, Rosati M, et al. (2012): Role of mast cells in innate and adaptive immunity. J Biol Regul Homeost Agents 26: 193-201. 
29. Theoharides TC, Kalogeromitros D (2006): The critical role of mast cells in allergy and inflammation. Ann NY Acad Sci 1088: 78-99.

30. Marshall JS (2004): Mast-cell responses to pathogens. Nat Rev Immunol 4: 787-799.

31. Brzezińska-Błaszczyk E, Rdzany RS (2005): The role of mast cells in innate immunity in antibacterial defense. Postepy Hig Med Dosw 59: 544-553.

32. Witczak P, Ewa Brzezińska-Błaszczyk E (2012): Mast cells in viral infections. Postepy Hig Med Dosw 66: 231-241.

33. Weller CL, Collington SJ, Williams T, Lamb JR (2011): Mast cells in health and disease. Clin Sci 120: 473-484.

34. Anand P, Singh B, Jaggi AS, Singh N (2012): Mast cells: an expanding pathophysiological role from allergy to other disorders. Naunyn Schmiedebergs Arch Pharmacol 385: 657-670.

35. Okayama Y, Kawakami T (2006): Development, migration, and survival of mast cells. Immunol Res 34: 97-115.

36. Liu C, Liu Z, Li Z, Wu Y (2010): Molecular regulation of mast cell development and maturation. Mol Biol Rep 37: 1993-2001.

37. Hu ZQ, Zhao WH, Shimamura T (2007): Regulation of mast cell development by inflammatory factors. Curr Med Chem 14: 3044-3050.

38. Hu ZQ, Asano K, Sek H, Shimamura T (1995): An essential role of prostaglandin $\mathrm{E}$ on mouse mast cell induction. J Immunol 155: 2134-2142.

39. Broudy VC (1997): Stem cell factor and hematopoiesis. Blood 90: $1345-1364$.

40. Shelburne CP, Ryan JJ (2001): The role of Th cytokines in mast cell homeostasis. Immunol Rev 179: 82-93.

41. Brzezińska-Błaszczyk E, Olejnik AK (2002): Cytokines modulate biology of tissue mast cells. Postepy Hig Med Dosw 56: 803-819.

42. Brzezińska-Błaszczyk E, Misiak-Tłoczek A (2007): The regulation of mast cell migration. Part 2: mast cell chemoattractants. Postepy Hig Med Dosw 28: 493-499.

43. Iemura A, Tsai M, Ando A, et al. (1994): The c-kit ligand, stem cell factor, promotes mast cell survival by suppressing apoptosis. Am J Pathol 144: 321-328.

44. Dastych J, Metcalfe DD (1994): Stem cell factor induces mast cell adhesion to fibronectin. J Immunol 152: 213-219.

45. Meininger CJ, Yano H, Rottapel R, et al. (1992): The c-kit receptor ligand functions as a mast cell chemoattractant. Blood 79: $958-963$

46. Columbo M, Horowitz EM, Botana LM, et al. (1992): The human recombinant c-kit receptor ligand, rhSCF, induces mediator release from human cutaneous mast cells and enhances IgE-dependent mediator release from both skin mast cells and peripheral blood basophils. J Immunol 149: 599-608.

47. Gagari E, Tsai M, Lantz CS, et al. (1997): Differential release of mast cell interleukin-6 via c-kit. Blood 89: 2654-2663.

48. Baghestanian M, Hofbauer R, Kiener HP, et al. (1997): The $c$-kit ligand stem cell factor and anti-IgE promote expression of monocyte chemoattractant protein-1 in human lung mast cells. Blood 90: 4438-4449.

49. Wershil BK, Tsai M, Geissler EN, et al. (1992): The rat $c$-kit ligand, stem cell factor, induces c-kit receptor-dependent mouse mast cell activation in vivo. Evidence that signaling through the $c$-kit receptor can induce expression of cellular function. $\mathrm{J}$ Exp Med 175: 245-255.

50. Bischoff SC, Dahinden CA (1992): c-kit ligand: a unique potentiator of mediator release by human lung mast cells. J Exp Med 175: 237-244.
51. Hundley TR, Gilfillan AM, Tkaczyk C, et al. (2004): Kit and Fc\&RI mediate unique and convergent signals for release of inflammatory mediators from human mast cells. Blood 104: 2410-2417.

52. Ito T, Smrž D, Jung MY, et al. (2012): Stem cell factor programs the mast cell activation phenotype. J Immunol 188 : 5428-5437.

53. Ando A, Martin TR, Galli SJ (1993): Effects of chronic treatment with the c-kit ligand, stem cell factor, on immunoglobulin E-dependent anaphylaxis in mice. Genetically mast celldeficient Sl/Sld mice acquire anaphylactic responsiveness, but the congenic normal mice do not exhibit augmented responses. J Clin Invest 92: 1639-1649.

54. Karra L, Berent-Maoz B, Ben-Zimra M, Levi-Schaffer F (2009): Are we ready to downregulate mast cells? Curr Opin Immunol 21: 708-714.

55. Li L, Yao Z (2004): Mast cell and immune inhibitory receptors. Cell Mol Immunol 1: 408-415.

56. Bąbolewska E, Brzezińska-Błaszczyk E (2012): Mast cell inhibitory receptors. Postepy Hig Med Dosw 66: 739-751.

57. Brzezińska-Błaszczyk E (2013): Modulacja FcєRI-zależnej aktywności komórek tucznych przez receptory hamujące. Alerg Astma Immunol (in press).

58. Castells MC, Klickstein LB, Hassani K, et al. (2001): gp49B1$\alpha v \beta 3$ interaction inhibits antigen-induced mast cell activation. Nat Immunol 2: 436-442.

59. Masuda A, Nakamura A, Maeda T, et al. (2007): Cis binding between inhibitory receptors and MHC class I can regulate mast cell activation. J Exp Med 204: 907-920.

60. Malbec O, Fridman WH, Daëron M (1999): Negative regulation of $c$-kit-mediated cell proliferation by FcyRIIB. J Immunol 162: 4424-4429.

61. Malbec O, Attal JP, Fridman WH, Daëron M (2002): Negative regulation of mast cell proliferation by Fc $\gamma$ RIIB. Mol Immunol 38: 1295-1299.

62. Bloom J, Cross FR (2007): Multiple levels of cyclin specificity in cell-cycle control. Nat Rev Mol Cell Biol 8: 149-160.

63. Malbec O, Schmitt C, Bruhns P, et al. (2001): Src homology 2 domain-containing inositol 5-phosphatase 1 mediates cell cycle arrest by Fc $\gamma$ RIIB. J Biol Chem 276: 30381-30391.

64. Wu HJ, Bondada S (2009): CD72, a coreceptor with both positive and negative effects on B lymphocyte development and function. J Clin Immunol 29: 12-21.

65. Alcón VL, Luther C, Balce D, Takei F (2009): B-cell co-receptor CD72 is expressed on NK cells and inhibits IFN- $\gamma$ production but not cytotoxicity. Eur J Immunol 39: 826-832.

66. Kataoka TR, Kumanogoh A, Bandara G, et al. (2010): CD72 negatively regulates KIT-mediated responses in human mast cells. J Immunol 184: 2468-2475.

67. Chen CC, Kong DW, Cooper MD, Kubagawa H (2002): Mast cell regulation via paired immunoglobulin-like receptor PIRB. Immunol Res 26: 191-197.

68. Bachelet I, Munitz A, Berent-Maoz B, et al. (2008): Suppression of normal and malignant kit signaling by a bispecific antibody linking kit with CD300a. J Immunol 180: 6064-6069.

69. Feldweg AM, Friend DS, Zhou JS, et al. (2003): gp49B1 suppresses stem cell factor-induced mast cell activation-secretion and attendant inflammation in vivo. Eur J Immunol 33: 22622268.

70. Horny HP, Sotlar K, Valent P (2007): Mastocytosis: state of the art. Pathobiology 74: 121-132.

71. El-Agamy DS (2012): Targeting $c$-kit in the therapy of mast cell disorders: current update. Eur J Pharmacol 690: 1-3. 